\title{
EFEITO DE PONTAS DE PULVERIZAÇÃO NO CONTROLE QUÍMICO DA FERRUGEM DA SOJA
}

\section{JOÃO P. A. R. DA CUNHA ${ }^{1}$, EUDES A. C. MOURA², JAIR L. DA SILVA JÚNIOR ${ }^{2}$, FLÁVIO A. ZAGO², FERNANDO C. JULIATTI ${ }^{3}$}

\begin{abstract}
RESUMO: O controle químico eficiente da ferrugem asiática da soja depende da correta seleção da ponta de pulverização. Este trabalho teve o objetivo de avaliar o efeito da utilização de diferentes pontas de pulverização na aplicação de fungicida para o controle da ferrugem da soja. $O$ ensaio foi conduzido no delineamento em blocos ao acaso, com quatro repetições, em esquema fatorial (4 x 2) +1 : quatro tipos de ponta de pulverização (jato plano defletor duplo, jato plano duplo com préorifício e jato cônico vazio com e sem indução de ar), dois volumes de aplicação (150 e $200 \mathrm{~L} \mathrm{ha}^{-1}$ ) e um tratamento adicional que não recebeu fungicida. Realizou-se a semeadura direta da cultivar de soja M-SOY 8008 (ciclo precoce), avaliando-se, após a aplicação do fungicida tebuconazole, a deposição de calda no dossel da cultura, a severidade da ferrugem, o grau de desfolha e a produtividade. Concluiu-se que não houve influência dos tipos de pontas de pulverização e dos volumes de calda no controle da ferrugem. Na parte inferior do dossel, a cobertura proporcionada com a utilização das quatro pontas foi inferior a 7\% da área, sendo, portanto, necessário buscar estratégias que incrementem essa deposição. O fungicida reduziu a severidade da ferrugem da soja, o que refletiu na produtividade, que foi, em média, 157\% superior à obtida na testemunha.
\end{abstract}

PALAVRAS-CHAVE: tecnologia de aplicação, Glycine max L., Phakopsora pachyrhizi.

\section{SPRAY NOZZLE EFFECT ON SOYBEAN RUST CHEMICAL CONTROL}

ABSTRACT: Soybean rust chemical control depends on the correct selection of the spray nozzles. This study evaluated the spray nozzle effect on soybean rust control application. A randomized complete-block design with four replications was used, in a factorial model $(4 \times 2)+1$ : four spray nozzles (hollow cone spray nozzles, with and without air induction, pre-orifice twin flat fan and turbo twin flat fan), two spray volumes (150 and $200 \mathrm{~L} \mathrm{ha}^{-1}$ ) and the control (non-treated plot). MSOY 8008 soybean (early cycle) was sown. After the application of the fungicide tebuconazole, with the different nozzles and volume rates, the spray deposition on the plant canopy, rust severity, defoliation level and yield were evaluated. The results showed that there was no influence of the nozzle type neither of the application volume in rust control. In the canopy lower part, the coverage obtained with the four nozzles was less than $7 \%$ of the area, therefore, it is necessary to find strategies to increase that deposition. The fungicide decreased rust severity, increasing soybean yield, which was, on average, $157 \%$ greater than that obtained in the control.

KEYWORDS: application technology, Glycine max L., Phakopsora pachyrhizi.

\section{INTRODUÇÃO}

A ferrugem da soja (Glycine max (L.) Merrill) causada por Phakopsora pachyrhizi H. Sydow \& Sydow foi relatada pela primeira vez no Brasil, no final da safra de 2000/2001, representando grande ameaça para todos os países do continente americano (GODOY \& CANTERI, 2004).

\footnotetext{
${ }^{1}$ Eng ${ }^{0}$ Agrícola, Prof. Doutor, Instituto de Ciências Agrárias, Universidade Federal de Uberlândia, Câmpus Umuarama, Uberlândia MG, Fone: (0XX34) 3218.2225, jpcunha@iciag.ufu.br

${ }^{2}$ Estudante do Curso de Agronomia, Instituto de Ciências Agrárias, Universidade Federal de Uberlândia, Câmpus Umuarama, Uberlândia - MG.

${ }^{3}$ Eng ${ }^{\mathbf{o}}$ Agrônomo, Prof. Doutor, Instituto de Ciências Agrárias, Universidade Federal de Uberlândia, Câmpus Umuarama, Uberlândia - MG.
}

Recebido pelo Conselho Editorial em: 25-5-2007

Aprovado pelo Conselho Editorial em: 5-4-2008 
Segundo SANTOS at al. (2007), a ferrugem asiática tem seu controle baseado principalmente em fungicidas. Embora sejam eficientes, o controle da doença, muitas vezes, não tem sido satisfatório, e uma das razões se deve ao fato de o produto ser aplicado de forma inadequada. Para JULIATTI et al. (2005), o manejo correto da doença passa pelas estratégias de redução da dispersão de inóculo (vazio sanitário e parcelas armadilhas - sentinelas), uso da resistência parcial, fungicidas de maior eficácia e tecnologia de aplicação adequada aos sistemas de produção, caso contrário o atual sistema de produção será insustentável.

A doença, em geral, ocorre inicialmente nas partes mais baixas da cultura e, dessa forma, as aplicações de fungicida precisam vencer a barreira imposta pela massa de folhas, com o objetivo de promover boa cobertura da planta (RAETANO, 2007). Uma das formas de obter maior deposição do ingrediente ativo sob alvos biológicos é a seleção correta das pontas de pulverização.

Para a aplicação de fungicidas na cultura da soja, pontas muito utilizadas são aquelas que produzem gotas finas. No entanto, em virtude de o seu espectro de gotas propiciar a deriva, tem-se tentado utilizar pontas que produzam gotas maiores, como as de jato plano com pré-orifício e jato plano com indução de ar. Essas, no entanto, podem comprometer a cobertura das plantas, em razão de as gotas serem de maior tamanho. Conseqüentemente, poderá haver menor controle de doenças. De forma geral, gotas pequenas são facilmente transportadas pelo vento, porém propiciam maior cobertura do alvo, condição desejada, sobretudo, quando da utilização de agrotóxicos protetores (CUNHA et al., 2006).

Outra variável importante na aplicação de fungicidas é o volume de calda e, atualmente, existe tendência em reduzir esse volume. O uso de menor volume de água misturada ao ingrediente ativo aumenta a autonomia e a capacidade operacional dos pulverizadores, diminuindo os custos da aplicação; no entanto, requer aprimoramento da tecnologia de aplicação empregada no campo para a obtenção de boa cobertura do alvo desejado.

A recomendação tradicional para a aplicação de fungicidas sempre esteve ligada às pontas de jato cônico vazio, no entanto, em virtude de problemas com deriva, seu uso tem sido bastante restrito, principalmente em regiões de vento intenso. Por essa razão, a indústria lançou recentemente no mercado as pontas de jato cônico vazio com indução de ar. Ela tenta aliar a capacidade de penetração das gotas, promovida pelo movimento rotacional do jato e pela pressão de trabalho mais elevada, com a menor suscetibilidade à deriva (BARBER \& LANDERS, 2006). Nos últimos anos, o uso de pontas com indução de ar, que geram gotas de maior tamanho, tem sido bastante incentivado pelo potencial de redução de deriva e boa eficácia em vários tratamentos (KNEWITZ et al., 2002). Contudo, por não existir estudo a respeito da utilização de pontas de jato cônico vazio com indução de ar para aplicação de agrotóxicos em culturas anuais de baixo porte, como a soja, é preciso avaliálas de forma a verificar se as mesmas proporcionam cobertura adequada do alvo, principalmente nas partes inferiores da cultura.

Outras pontas também recém-lançadas no mercado mundial, e ainda pouco avaliadas, são as pontas de jato plano defletor duplo e as pontas de jato plano duplo com pré-orifício. Elas tentam aliar as vantagens das pontas de jato plano duplo, principalmente a capacidade de penetração, ao espectro de gotas médias, menos suscetível à deriva do que o espectro de gotas finas, e com maior capacidade de cobertura do que o espectro de gotas grossas.

Dessa forma, o presente trabalho teve como objetivo avaliar o controle químico da ferrugem asiática da soja, em função do uso de diferentes tipos de pontas de pulverização e volumes de aplicação.

\section{MATERIAL E MÉTODOS}

O presente trabalho foi conduzido na Fazenda Experimental Capim Branco, pertencente à Universidade Federal de Uberlândia. Realizou-se a semeadura direta da cultivar de soja M-SOY 8008 (ciclo precoce), no dia 6-12-2006, utilizando-se do espaçamento entre fileiras de $45 \mathrm{~cm}$. 
O ensaio foi conduzido no delineamento em blocos ao acaso, com quatro repetições, em esquema fatorial $(4 \times 2)+1$ : quatro tipos de ponta de pulverização (jato plano defletor duplo, jato plano duplo com pré-orifício, jato cônico vazio com indução de ar e jato cônico vazio), dois volumes de aplicação (150 e $\left.200 \mathrm{~L} \mathrm{ha}^{-1}\right)$ e um tratamento adicional que não recebeu fungicida (testemunha).

Utilizou-se do fungicida sistêmico com ingrediente ativo tebuconazole, pertencente ao grupo químico dos triazóis (formulação concentrado emulsionável), na dose recomendada pelo fabricante (100 $\mathrm{g} \mathrm{ha}^{-1}$ de ingrediente ativo). A aplicação foi realizada utilizando-se de pulverizador costal de pressão constante $\left(\mathrm{CO}_{2}\right)$, dotado de uma barra com disposição simultânea de quatro pontas espaçadas de $50 \mathrm{~cm}$. Para as pontas de jato plano, empregou-se a pressão de $200 \mathrm{kPa}$, e para as pontas de jato cônico vazio, $400 \mathrm{kPa}$. As velocidades de deslocamento variaram de 4,0 a 5,5 km, tendo em vista o uso do pulverizador costal. A variação do volume de pulverização foi realizada alterando-se a velocidade de avanço (controlada por um passômetro), visando a não alterar o espectro de gotas para um mesmo jogo de ponta. A altura de aplicação em relação à cultura foi de $50 \mathrm{~cm}$.

Utilizaram-se pontas de pulverização hidráulicas, selecionadas de forma a se obterem os volumes de aplicação testados (Tabela 1). As pontas de jato plano defletor duplo apresentam duas superfícies de impacto que produzem dois jatos planos defasados de $60^{\circ}$. As pontas de jato plano duplo com pré-orifício apresentam um orifício antes da abertura dupla, com dois orifícios elípticos para a saída de jatos planos, com ângulo de $60^{\circ}$ entre eles, o que permite a formação de gotas de maior diâmetro, comparadas às pontas sem o pré-orifício. As pontas de jato cônico com indução de ar possuem um sistema venturi que faz com que as gotas se tornem mais grossas (com bolhas de ar em seu interior) do que as produzidas pelas pontas de jato cônico padrão.

TABELA 1. Descrição das pontas utilizadas. Spray nozzle specifications.

\begin{tabular}{lccc}
\hline Ponta & Descrição & Fabricante & DMV* \\
\hline TVI 80-015 & Jato cônico vazio com indução de ar & Albuz & $646 \mu \mathrm{m}(500 \mathrm{kPa})$ \\
JA-2 & Jato cônico vazio & Jacto & $153 \mu \mathrm{m}(414 \mathrm{kPa})$ \\
TTJ60 110-02 & Jato plano duplo defletor & Teejet & $284 \mu \mathrm{m}(200 \mathrm{kPa})$ \\
DGTJ60 110-02 & Jato plano duplo com pré-orifício & Teejet & $218 \mu \mathrm{m}(200 \mathrm{kPa})$ \\
\hline $\begin{array}{l}\text { * Diâmetro da mediana volumétrica indicado pelo fabricante. O número entre parênteses indica a pressão de trabalho } \\
\text { testada pelo fabricante para o DMV fornecido. }\end{array}$
\end{tabular}

O fungicida foi aplicado com as diferentes pontas e volumes de calda, em três épocas, com intervalos de aproximadamente 21 dias. A primeira aplicação foi realizada no estágio $\mathrm{V}_{7}$, com $\mathrm{o}$ dossel da cultura proporcionando $90 \%$ de cobertura da área. Nesse estágio, a soja apresentava severidade de 3\% de ferrugem nas folhas inferiores do dossel da cultura. Na parte superior, ainda não havia sintomas da doença. A segunda aplicação foi realizada no estágio $R_{3}$, e a terceira, no estágio $\mathrm{R}_{5}$, ambas com fechamento total da cultura.

Foram realizadas uma aplicação de inseticida e duas aplicações de herbicida pós-emergente de forma semelhante em toda a área. A avaliação da eficácia do fungicida no controle da ferrugem da soja, considerando os quatro tipos de pontas e os dois volumes de aplicação, foi feita mediante a comparação da severidade da doença e da produtividade entre parcelas tratadas com fungicida e parcelas não-tratadas (testemunha). Também foi conduzido o estudo de deposição da calda de fungicida pulverizada, considerando as parcelas que receberam o produto.

Esse estudo foi realizado analisando-se a distribuição de fungicida sobre a cultura da soja, por meio da quantificação das gotas depositadas em papéis sensíveis à água (76 x $26 \mathrm{~mm})$. Antes da pulverização, foram marcadas cinco plantas, escolhidas ao acaso, em cada parcela, e, em cada planta, foram colocadas duas etiquetas de papel hidrossensível: uma na parte superior, junto à face adaxial da folha, e outra na parte inferior da planta, também junto à face adaxial da folha. 
Posteriormente, foram feitas a quantificação e a caracterização dos impactos em cada etiqueta. Para isso, após a segunda e a terceira aplicações, as etiquetas foram digitalizadas por meio de um scanner (resolução espacial de 600 dpi não-interpolados, com cores em 24 bits) e analisadas, utilizando-se do programa computacional E-Sprinkle (versão 2005b), específico para essa finalidade. Esse programa utiliza o fator de espalhamento recomendado pelo fabricante dos papéis hidrossensíveis. Empregou-se o módulo DropCap para a captura das gotas digitalizadas e, em seguida, determinaram-se o número de gotas por centímetro quadrado e a percentagem de área coberta. Na primeira aplicação, devido à umidade do ar elevada (próxima a 80\%), as etiquetas não puderam ser digitalizadas com o devido contraste, procedendo-se apenas à contagem do número de impactos por centímetro quadrado, de forma manual, com o auxílio de uma lupa de aumento (10x).

A avaliação da severidade da ferrugem foi realizada a intervalos de aproximadamente 20 dias, totalizando quatro avaliações. A primeira avaliação da severidade foi feita aos 38 dias após a emergência (DAE). Para tal, utilizou-se da escala diagramática proposta por GODOY et al. (2006). $\mathrm{Na}$ avaliação, marcaram-se dez plantas, escolhidas ao acaso, em cada parcela, e, em cada planta, três folhas localizadas nos terços inferior, médio e superior da planta. As médias dessas avaliações constituíram a severidade média da doença. Também foi realizada uma avaliação do grau de desfolha, em percentagem, aos 80 DAE.

Com os dados da severidade da doença, procedeu-se à construção da curva de progresso e à determinação da área abaixo da curva de progresso da doença (AACPD). Essa foi calculada pelo somatório das áreas trapezoidais, conforme metodologia proposta por CAMPBELL \& MADDEN (1990).

A colheita foi realizada aos 110 DAE, sendo avaliada a massa de 1.000 grãos e a produtividade nas parcelas experimentais, de $10,8 \mathrm{~m}^{2}(6 \times 1,8 \mathrm{~m})$, constituídas de quatro fileiras de $6 \mathrm{~m}$ de comprimento. A massa dos grãos foi corrigida para o conteúdo de água de $13 \%$ (b.u.).

Durante as aplicações do fungicida, monitoraram-se as condições ambientais de temperatura, umidade relativa do ar e velocidade do vento. Durante a primeira aplicação, a temperatura do ar variou de 25 a $27{ }^{\circ} \mathrm{C}$, a umidade de 74 a $85 \%$ e a velocidade do vento de 4 a $6 \mathrm{~km} \mathrm{~h}^{-1}$. Na segunda, a temperatura variou de 26 a $27^{\circ} \mathrm{C}$, a umidade de 62 a $70 \%$ e a velocidade do vento de 5 a $7 \mathrm{~km} \mathrm{~h}^{-1}$. $\mathrm{Na}$ terceira, a temperatura variou de 27 a $29^{\circ} \mathrm{C}$, a umidade de 55 a $65 \%$ e a velocidade do vento de 6 a $8 \mathrm{~km} \mathrm{~h}^{-1}$.

Os dados de deposição foram submetidos à análise de variância, e as médias, comparadas pelo teste Tukey, a 5\% de significância. Os dados de severidade de ferrugem, massa de 1.000 grãos, percentagem de desfolha e produtividade foram submetidos à analise de variância, e as médias das parcelas tratadas com fungicidas foram comparadas à testemunha, utilizando-se do teste de Dunnett, a 5\% de significância.

\section{RESULTADOS E DISCUSSÃO}

Na Tabela 2, apresentam-se as médias da densidade de gotas depositadas nas partes superior e inferior do dossel da cultura da soja, após as três aplicações de fungicida. Com exceção da posição superior na primeira aplicação, a interação entre ponta e volume de aplicação não foi significativa a $5 \%$ de probabilidade, pelo teste $\mathrm{F}$, indicando a independência entre os dois fatores.

Com relação às quatro pontas, observou-se a tendência de a ponta de jato cônico vazio proporcionar maior deposição de gotas, enquanto a ponta de jato cônico vazio com indução de ar proporcionou a menor deposição. Na posição inferior do dossel, nas três aplicações, as pontas TTJ60, DGTJ60 e TVI apresentaram-se iguais quanto à densidade de gotas depositadas, e inferiores à ponta $\mathrm{JA}$.

A ponta de jato cônico vazio gera gotas de menor tamanho que, auxiliadas pelo movimento rotacional do jato, penetram no dossel da cultura, aumentando a deposição sobre o alvo. Entretanto, maiores riscos de perdas por deriva podem ocorrer em aplicações com esse tipo de ponta e padrão 
de gotas. ANTUNIASSI et al. (2004) e CUNHA et al. (2006), avaliando a deposição promovida por diferentes pontas, constataram maior cobertura da parte inferior do dossel da cultura da soja quando se empregaram pontas com tamanho de gota menor.

TABELA 2. Densidade de gotas depositadas $\left(\right.$ gotas $\mathrm{cm}^{-2}$ ) nas partes superior e inferior do dossel da cultura da soja, após a aplicação de fungicida com diferentes pontas de pulverização, em dois volumes de aplicação. Droplet density (droplets $\mathbf{c m}^{-2}$ ) on top and lower soybean canopy, after fungicide application with different nozzles, in two spray volumes.

\begin{tabular}{|c|c|c|c|c|c|c|}
\hline \multirow{3}{*}{ Ponta } & \multicolumn{3}{|c|}{ Posição Superior } & \multicolumn{3}{|c|}{ Posição Inferior } \\
\hline & \multicolumn{2}{|c|}{$\begin{array}{l}\text { Volume de Aplicação } \\
\qquad\left(\mathrm{L} \mathrm{ha}^{-1}\right)\end{array}$} & \multirow[t]{2}{*}{ Média } & \multicolumn{2}{|c|}{$\begin{array}{l}\text { Volume de Aplicação } \\
\qquad\left(\mathrm{L} \mathrm{ha}^{-1}\right)\end{array}$} & \multirow[t]{2}{*}{ Média } \\
\hline & 200 & 150 & & 200 & 150 & \\
\hline \multicolumn{7}{|c|}{ Densidade de gotas depositadas na $1^{\mathrm{a}}$ aplicação $\left(\right.$ gotas $\left.\mathrm{cm}^{-2}\right)$} \\
\hline TTJ60 110-02 & $131,7 \mathrm{~b}$ & $95,0 \mathrm{a}$ & 113,3 & 23,3 & 26,7 & $25,0 \mathrm{~b}$ \\
\hline DGTJ60 110-02 & $50,0 \mathrm{c}$ & $42,7 \mathrm{~b}$ & 46,3 & 22,0 & 8,0 & $15,0 \mathrm{~b}$ \\
\hline TVI 80-015 & $24,0 \mathrm{c}$ & $13,0 \mathrm{~b}$ & 18,5 & 12,0 & 4,3 & $8,2 \mathrm{~b}$ \\
\hline JA-2 & $216,7 \mathrm{a}$ & $198,0 \mathrm{a}$ & 207,4 & 140 & 93,3 & $116,7 \mathrm{a}$ \\
\hline Média & $105,0 \mathrm{~A}$ & $87,2 \mathrm{~A}$ & & $49,3 \mathrm{~A}$ & $33,1 \mathrm{~A}$ & \\
\hline \multicolumn{7}{|c|}{ Densidade de gotas depositadas na $2^{\underline{a}}$ aplicação $\left(\right.$ gotas $\left.\mathrm{cm}^{-2}\right)$} \\
\hline TTJ60 110-02 & 160,4 & 179,3 & $169,8 \mathrm{a}$ & 34,3 & 22,3 & $28,3 \mathrm{~b}$ \\
\hline DGTJ60 110-02 & 166,0 & 159,2 & $162,6 \mathrm{a}$ & 29,1 & 13,9 & $21,5 \mathrm{~b}$ \\
\hline TVI $80-015$ & 63,1 & 52,0 & $57,5 \mathrm{~b}$ & 13,2 & 10,7 & $12,0 \mathrm{~b}$ \\
\hline JA-2 & 228,5 & 188,3 & $208,4 \mathrm{a}$ & 72,1 & 25,9 & $49,0 \mathrm{a}$ \\
\hline Média & $154,5 \mathrm{~A}$ & $144,7 \mathrm{~A}$ & & $37,2 \mathrm{~A}$ & $18,2 \mathrm{~A}$ & \\
\hline \multicolumn{7}{|c|}{ Densidade de gotas depositadas na $3^{\mathrm{a}}$ aplicação $\left(\right.$ gotas cm $\left.{ }^{-2}\right)$} \\
\hline TTJ60 110-02 & 160,0 & 142,8 & $151,5 \mathrm{a}$ & 36,8 & 20,4 & $28,6 \mathrm{~b}$ \\
\hline DGTJ60 110-02 & 160,9 & 151,1 & $156,0 \mathrm{a}$ & 45,3 & 20,6 & $33,1 \mathrm{~b}$ \\
\hline TVI 80-015 & 43,9 & 62,5 & $53,2 \mathrm{~b}$ & 11,0 & 13,6 & $12,3 \mathrm{~b}$ \\
\hline JA-2 & 232,0 & 227,4 & $229,7 \mathrm{a}$ & 98,4 & 74,1 & 86,2 a \\
\hline Média & $146,0 \mathrm{~A}$ & $149,2 \mathrm{~A}$ & & $47,9 \mathrm{~A}$ & $32,2 \mathrm{~A}$ & \\
\hline
\end{tabular}

Com relação ao volume de aplicação, não foi encontrada diferença na densidade de gotas depositadas, tanto na posição superior quanto na inferior do dossel. De qualquer forma, observou-se tendência de aumento da deposição com o incremento do volume de aplicação. Em geral, espera-se que o incremento do volume de aplicação propicie aumento do volume de calda retido até certo ponto, a partir do qual a superfície não mais retém o líquido, passando a ocorrer o escorrimento, o que não é desejável. Em trabalho realizado por DERKSEN \& SANDERSON (1996), avaliando a influência do volume de calda (47 a $1.870 \mathrm{~L} \mathrm{ha}^{-1}$ ) na deposição foliar de agrotóxicos, verificaram-se também melhor cobertura e menores variações de deposição ao longo do dossel com o uso de maiores volumes de aplicação.

Na Tabela 3, tem-se a cobertura proporcionada pelas gotas depositadas. Diferentemente do resultado de deposição, expresso em densidade de gotas, a cobertura em percentagem foi semelhante para as quatro pontas na posição inferior. Isso se deve ao tamanho das gotas geradas. A ponta de jato cônico sem indução de ar, apesar de ter proporcionado maior quantidade de gotas no alvo, apresentou a mesma percentagem de cobertura que as demais pontas, em virtude de suas gotas serem de tamanho bastante reduzido.

ANTUNIASSI et al. (2004) verificaram os piores resultados de deposição na parte inferior da cultura da soja utilizando pontas com indução de ar. No entanto, esses autores avaliaram pontas com indução de ar de jato plano, o que pode explicar o resultado encontrado. 
Na posição superior, a ponta TVI proporcionou a menor deposição. A utilização de pontas com indução de ar gera gotas grossas, o que pode dificultar a boa deposição. Sua utilização, portanto, deve ser bastante criteriosa. Neste trabalho, por serem as pontas de indução de ar de jato cônico vazio e não de jato plano, o efeito negativo da baixa cobertura do alvo na parte inferior promovido por gotas grossas foi reduzido. De qualquer forma, a ponta TVI, apesar do movimento rotacional proporcionado pelo jato cônico, não proporcionou boa penetração no dossel da cultura. Provavelmente, a pressão empregada $(400 \mathrm{kPa})$ não foi suficiente para quebrar as gotas de forma mais adequada e fornecer energia para a transposição do obstáculo proporcionado pela barreira de folhas. É possível que, em maiores pressões, essa ponta apresente comportamento diferenciado de deposição, em virtude da diminuição do tamanho das gotas.

TABELA 3. Cobertura de gotas depositadas (\%) nas partes superior e inferior do dossel da cultura da soja, após a aplicação de fungicida com diferentes pontas de pulverização, em dois volumes de aplicação. Droplet coverage (\%) on top and lower soybean canopy, after fungicide application with different nozzles, in two spray volumes.

\begin{tabular}{|c|c|c|c|c|c|c|}
\hline \multirow{3}{*}{ Ponta } & \multicolumn{3}{|c|}{ Posição Superior } & \multicolumn{3}{|c|}{ Posição Inferior } \\
\hline & \multicolumn{2}{|c|}{$\begin{array}{l}\text { Volume de Aplicação } \\
\left(\mathrm{L} \mathrm{ha}^{-1}\right)\end{array}$} & \multirow[t]{2}{*}{ Média } & \multicolumn{2}{|c|}{$\begin{array}{c}\text { Volume de Aplicação } \\
\left(\mathrm{L} \mathrm{ha}^{-1}\right)\end{array}$} & \multirow[t]{2}{*}{ Média } \\
\hline & 200 & 150 & & 200 & 150 & \\
\hline \multicolumn{7}{|c|}{ Cobertura do alvo na $2^{\mathrm{a}}$ aplicação $(\%)$} \\
\hline TTJ60 110-02 & 54,0 & 67,1 & $60,5 \mathrm{a}$ & 10,2 & 2,8 & $6,5 \mathrm{a}$ \\
\hline DGTJ60 110-02 & 52,2 & 53,6 & 52,9 a & 7,3 & 2,9 & $5,1 \mathrm{a}$ \\
\hline TVI 80-015 & 38,7 & 25,8 & $32,3 \mathrm{~b}$ & 7,9 & 3,1 & $5,5 \mathrm{a}$ \\
\hline JA-2 & 50,8 & 45,4 & $48,1 \mathrm{ab}$ & 7,0 & 3,6 & $5,3 \mathrm{a}$ \\
\hline Média & $48,9 \mathrm{~A}$ & $48,0 \mathrm{~A}$ & & $8,1 \mathrm{~A}$ & $3,1 \mathrm{~A}$ & \\
\hline \multicolumn{7}{|c|}{ Cobertura do alvo na $3^{\mathrm{a}}$ aplicação (\%) } \\
\hline TTJ60 110-02 & 53,2 & 73,1 & $63,2 \mathrm{a}$ & 5,6 & 1,9 & $3,7 \mathrm{a}$ \\
\hline DGTJ60 110-02 & 71,5 & 76,2 & 73,9 a & 8,7 & 3,0 & $5,9 \mathrm{a}$ \\
\hline TVI 80-015 & 20,9 & 42,4 & $31,6 \mathrm{~b}$ & 4,7 & 8,7 & $6,7 \mathrm{a}$ \\
\hline JA-2 & 54,0 & 37,4 & $45,7 \mathrm{ab}$ & 7,3 & 6,6 & $7,0 \mathrm{a}$ \\
\hline Média & $49,9 \mathrm{~A}$ & $57,3 \mathrm{~A}$ & & $6,6 \mathrm{~A}$ & $5,1 \mathrm{~A}$ & \\
\hline
\end{tabular}

Com relação ao volume de aplicação, não foram observadas diferenças nas duas aplicações. É possível notar, também, grande desuniformidade de cobertura. Em virtude do fechamento da cultura, promovido pelo crescimento das plantas de soja, a deposição na parte superior foi muito maior que na parte inferior. No caso de doenças que tenham seu desenvolvimento inicial na parte baixeira, esse tipo de aplicação pode não ser eficiente, comprometendo o desenvolvimento da cultura. O aumento do volume de aplicação de 150 para $200 \mathrm{~L} \mathrm{ha}^{-1}$ não foi suficiente para amenizar esse problema.

Não ocorreram condições propícias à deriva durante as aplicações do fungicida, o que auxiliou os resultados obtidos. Possivelmente, em condições de vento acentuado, as gotas pequenas produzidas pelas pontas apresentariam maior risco de perdas por deriva e, conseqüentemente, menor deposição.

Com relação à avaliação da eficiência do controle químico, a ferrugem foi a doença que atacou a soja com maior intensidade. A doença apresentou os primeiros sintomas desde o início do ciclo da cultura $\left(\mathrm{V}_{4}\right)$, mostrando-se bastante agressiva. Nas parcelas tratadas com fungicida, mostrou comportamento similar, reduzindo a severidade da doença, contrastando com o que ocorreu na testemunha. Isso mostra a eficácia do fungicida tebuconazole no controle da doença.

O efeito das pontas e dos volumes de aplicação no controle da ferrugem é mostrado na Tabela 4. Nota-se, pela análise de variância, que não houve diferença entre as pontas e entre os volumes. 
Somente houve diferença entre as parcelas tratadas e a testemunha. Dessa forma, procedeu-se ao desdobramento dessa interação, utilizando-se do teste de Dunnett (Tabela 5). Todos os tratamentos que receberam fungicida superaram a testemunha em produtividade, indicando o controle da doença. As diferenças induzidas pelos efeitos das pontas e dos volumes de calda nos níveis de controle foram insuficientes para afetar a massa dos grãos e o rendimento da cultura.

TABELA 4. Resumo da análise de variância da produtividade da soja, da massa de 1.000 grãos, do grau de desfolha e dos dados de área abaixo da curva de progresso (AACP) da ferrugem, em função da aplicação de fungicida com diferentes pontas e volumes de calda. Variance analysis summary of soybean yield, 1000-grain weight, defoliation level and area under the rust progress curve (AURPC) affected by spray volumes and nozzles.

\begin{tabular}{|c|c|c|c|c|c|}
\hline $\begin{array}{l}\text { Fontes de } \\
\text { Variação }\end{array}$ & GL & $\begin{array}{c}\text { Significância do } \\
\text { Quadrado Médio da } \\
\text { AACP da Ferrugem* }\end{array}$ & $\begin{array}{l}\text { Significância do } \\
\text { Quadrado Médio da } \\
\text { Desfolha* }\end{array}$ & $\begin{array}{l}\text { Significância do } \\
\text { Quadrado Médio da } \\
\text { Massa de } 1.000 \\
\text { Grãos* }\end{array}$ & $\begin{array}{l}\text { Significância do } \\
\text { Quadrado Médio } \\
\text { da Produtividade* }\end{array}$ \\
\hline Ponta & 3 & Não-significativo & Não-significativo & Não-significativo & Não-significativo \\
\hline Volume & 1 & Não-significativo & Não-significativo & Não-significativo & Não-significativo \\
\hline Volume x Ponta & 3 & Não-significativo & Não-significativo & Não-significativo & Não-significativo \\
\hline $\begin{array}{l}\text { Fatorial } \mathrm{x} \\
\text { Testemunha }\end{array}$ & 1 & Significativo & Significativo & Significativo & Significativo \\
\hline C.V. (\%) & & 17,6 & 15,4 & 6,5 & 14,9 \\
\hline
\end{tabular}

* Significativo a $1 \%$ de probabilidade, pelo teste $\mathrm{F}$.

TABELA 5. Efeito do tipo de ponta de pulverização e do volume de calda, utilizados na aplicação de fungicida, na área abaixo da curva de progresso (AACP) da ferrugem, no grau de desfolha aos 80 DAE, na massa de 1.000 grãos e na produtividade da soja. Effects of spray volume and nozzles, used in fungicide application, on area under the rust progress curve (AURPC), defoliation level at $80 \mathrm{DAE}, 1000$-grain weight and soybean yield.

\begin{tabular}{lccccc}
\hline Ponta & $\begin{array}{c}\text { Volume de } \\
\text { Aplicação } \\
\left(\mathrm{L} \mathrm{ha}^{-1}\right)\end{array}$ & $\begin{array}{c}\text { AACP da } \\
\text { Ferrugem }\end{array}$ & $\begin{array}{c}\text { Desfolha } \\
(\%)\end{array}$ & $\begin{array}{c}\text { Massa de 1.000 } \\
\text { Grãos }(\mathrm{g})\end{array}$ & $\begin{array}{c}\text { Produtividade } \\
\left.(\mathrm{kg} \mathrm{ha})^{-1}\right)\end{array}$ \\
\hline TTJ60 110-02 & 200 & $457,4^{*}$ & $53,3^{*}$ & $104,3^{*}$ & $1.935,7^{*}$ \\
DGTJ60 110-02 & 200 & $373,2^{*}$ & $53,3^{*}$ & $105,9^{*}$ & $1.710,3^{*}$ \\
TVI 80-015 & 200 & $483,6^{*}$ & $56,7^{*}$ & $100,4^{*}$ & $1.917,7^{*}$ \\
JA-2 & 200 & $463,4^{*}$ & $60,0^{*}$ & $104,4^{*}$ & $1.974,3^{*}$ \\
TTJ60 110-02 & 150 & $420,4^{*}$ & $53,3^{*}$ & $102,7^{*}$ & $1.905,0^{*}$ \\
DGTJ60 110-02 & 150 & $444,6^{*}$ & $60,0^{*}$ & $106,4^{*}$ & $1.850,7^{*}$ \\
TVI 80-015 & 150 & $420,3^{*}$ & $56,7^{*}$ & $107,7^{*}$ & $1.796,7^{*}$ \\
JA-2 & 150 & $566,1^{*}$ & $63,3^{*}$ & $100,1^{*}$ & $1.732,3^{*}$ \\
\hline Testemunha & & $1.579,1$ & 96,6 & 83,9 & 720,7 \\
\hline
\end{tabular}

Médias seguidas por um asterisco diferem significativamente da testemunha, a 5\% de probabilidade, pelo teste de Dunnett.

A aplicação do fungicida promoveu aumento médio de produtividade de $157 \%$ em relação à testemunha, evidenciando que o controle da ferrugem foi viável e necessário, independentemente do tipo de ponta ou do volume de calda. Os resultados encontrados concordam com o trabalho de BOLLER et al. (2002). Os autores obtiveram resultados semelhantes de produtividade de soja aplicando fungicida sistêmico para o controle de oídio (Microsphaera diffusa Cooke \& Peck), com diferentes pontas, indicando haver possibilidade de se dar preferência àquelas com menor risco de deriva. CUNHA et al. (2006) também encontraram resultados semelhantes avaliando o controle químico da ferrugem asiática da soja com diferentes pontas de pulverização. 
A inexistência de diferença significativa na massa e no rendimento dos grãos, entre as parcelas tratadas com o fungicida, pode ser atribuída ao fato de que, mesmo sendo significativas as diferenças entre a densidade de gotas depositadas com as diferentes pontas na posição inferior do dossel, quando se levou em conta a cobertura em percentagem, ela foi semelhante na posição inferior, local crítico para o controle da ferrugem. O fato de trabalhar com fungicida sistêmico e em condições climáticas favoráveis durante as aplicações, também deve ter corroborado os resultados apresentados.

\section{CONCLUSÕES}

Não houve influência dos tipos de ponta de pulverização (jato plano defletor duplo, jato plano duplo com pré-orifício, jato cônico vazio com indução de ar e jato cônico vazio padrão) e dos volumes de calda ( 150 e $200 \mathrm{~L} \mathrm{ha}^{-1}$ ) no controle da ferrugem e na produtividade da cultura da soja.

Na parte inferior do dossel, a cobertura proporcionada com a utilização das quatro pontas foi inferior a $7 \%$ da área, o que pode prejudicar a eficiência dos tratamentos. É preciso buscar estratégias que incrementem a deposição de fungicida na parte inferior do dossel.

O fungicida tebuconazole reduziu a severidade da ferrugem, o que refletiu na produtividade, que foi, em média, $157 \%$ superior à obtida na testemunha.

\section{AGRADECIMENTOS}

À Fundação de Amparo à Pesquisa do Estado de Minas Gerais (FAPEMIG), pelo suporte financeiro que permitiu o desenvolvimento deste trabalho de pesquisa.

\section{REFERÊNCIAS}

ANTUNIASSI, U.R.; CAMARGO, T.V.; BONELLI, M.A.P.O.; ROMAGNOLE, E.W.C. Avaliação da cobertura de folhas de soja em aplicações terrestres com diferentes tipos de pontas. In: SIMPÓSIO INTERNACIONAL DE TECNOLOGIA DE APLICAÇÃO DE AGROTÓXICOS, 3., 2004, Botucatu. Anais... Botucatu: FEPAF, 2004. p.48-51.

BARBER, J.A.S.; LANDERS, A. Taking the pressure off: advances in sprayer technology. Disponível em: www.nysaes.cornell.edu/ent/faculty/landers/pestapp/publications/veg/

Veg\%20resrsach\%20Onions\%20Paper.doc. Acesso em: 25 jun. 2006.

BOLLER, W.; FORCELINI, C.A.; BRAUN, E. Efeitos da utilização de diferentes pontas de pulverização no controle químico de oídio em soja. In: REUNIÃO DE PESQUISA DE SOJA DA REGIÃO SUL, 30., 2002, Cruz Alta. Anais... Cruz Alta: Fundacep-Fecotrigo, 2002. p.104.

CAMPBELL, C.L.; MADDEN, L.V. Introduction to plant disease epidemiology. New York: John Wiley \& Sons, 1990. 532 p.

CUNHA, J.P.A.R.; REIS E.F.; SANTOS R.O. Controle químico da ferrugem asiática da soja em função de ponta de pulverização e de volume de calda. Ciência Rural, Santa Maria, v.36, n.5, p.1.360-6, 2006.

DERKSEN, R.C.; SANDERSON, J.P. Volume, speed and distribution technique effects on poinsettia foliar deposit. Transactions of the ASAE, St. Joseph, v.39, n.1, p.5-9, 1996.

GODOY, C.V.; CANTERI, M.G. Efeitos protetor, curativo e erradicante de fungicidas no controle da ferrugem da soja causada por Phakopsora pachyrhizi, em casa de vegetação. Fitopatologia Brasileira, Brasília, v.29, n.1, p.97-101, 2004.

GODOY, C.V.; KOGA, L. J.; CANTERI, M. G. Diagrammatic scale for assessment of soybean rust severity. Fitopatologia Brasileira, Brasília, v.31, n.1, p.63-8, 2006. 
JULIATTI, F.C.; POLIZEL, A.C.; JULIATTI, F.C.; MOURA, E.A.C.; AZEVEDO, L.A. Uso da resistência parcial e efeito preventivo e curativo de fungicidas no controle da ferrugem asiática. In: WORKSHOP BRASILEIRO SOBRE A FERRUGEM ASIÁTICA, 1., 2005, Uberlândia. Anais... Uberlândia: UFU, 2005. p.115-33.

KNEWITZ, H.; WEISSER, P.; KOCH, H. Drift-reducing spray application in orchards and biological efficacy of pesticides. Aspects of Applied Biology, Wellesbourne, v.66, n.esp., p.231-6, 2002.

RAETANO, C.G. Assistência de ar e outros métodos de aplicação a baixo volume em culturas de baixo fuste: a soja como modelo. Summa Phytopathologica, Botucatu, v.33, p.105-6, 2007. Suplemento

SANTOS, J.A.; JULIATTI, F.C.; SANTOS, V.A.; POLIZEL, A.C.; JULIATTI, F.C.; HAMAWAKI, O.T. Caracteres epidemiológicos e uso da análise de agrupamento para resistência parcial à ferrugem da soja. Pesquisa Agropecuária Brasileira, Brasília, v.42, n.3, p.443-7, 2007. 